\title{
ANALISIS TINGKAT KESEHATAN BANK BERDASARKAN RISK-BASED BANK RATING DAN PENGARUHNYA TERHADAP HARGA SAHAM
}

\begin{abstract}
Penelitian ini bertujuan untuk menginvestigasi tingkat kesehatan bank berdasarkan risk-based bank rating(RBBR) dan pengaruhnya terhadap harga saham dengan menggunakan perspektif signaling theory untuk menjelaskan hubungan antar variabel. Data yang digunakan dalam penelitian ini adalah data sekunder, dengan teknik pengambilan sampel purposive sampling. Sampel yang memenuhi kriteria sebanyak 28 perusahaan dan teknik analisis data menggunakan persamaan regresi berganda dengan bantuan program SPSS versi 19. Hasil pengujian secara statistik menunjukkan bahwa Loan to Deposit Ratio (LDR) tidak terbukti berpengaruh positif terhadap harga saham. Sedangkan Good corporate governance, Return On Equity (ROE) dan Capital Adequacy Ratio(CAR) terbukti berpengaruh positif terhadap harga saham
\end{abstract}

Keywords: Loan to Deposit Ratio, Good corporate governance, Return On Equity dan Capital Adequacy Ratio

\section{PENDAHULUAN}

Bank merupakan lembaga intermediary, yang menghimpun dana dari masyarakat dalam bentuk simpanan dan menyalurkan kepada masyarakat dalam bentuk kredit dan atau bentuk lainnya dalam rangka meningkatkan taraf hidup rakyat banyak.

Kinerja keuangan bank merupakan gambaran kondisi keuangan bank pada suatu periode tertentu baik mencakup aspek penghimpunan dana maupun penyaluran dananya, sehingga mampu menghasilkan keuntungan yang tinggi. Kinerja keuangan bank yang baik akan menarik minat investor untuk menanamkan dananya ke bank tersebut melalui pasar modal. Semakin banyak investor yang ingin membeli atau menyimpan dananya dalam suatu saham, maka harga saham tentunya akan semakin naik. Begitu juga sebaliknya apabila semakin banyak investor yang akan menjual atau melepas suatu saham, maka harganya pun akan semakin bergerak turun (Kania, 2012). Bank yang dapat menjaga kinerjanya dengan baik terutama tingkat profitabilitasnya yang tinggi dan mampu membagikan deviden dengan baik serta prospek usahanya dapat selalu berkembang dan dapat memenuhi ketentuan prudential banking regulation dengan baik, maka maka dapat dikatakan tingkat kesehatan bank baik.

Terdapat beberapa regulasi dalam Penilaian Tingkat Kesehatan Bank Umum, antara lain melalui Peraturan Bank Indonesia Nomor 13/1/PBI/2011 tanggal 5 Januari 2011, bahwa bank wajib memelihara dan/ atau meningkatkan Tingkat Kesehatan Bank dengan menerapkan prinsip kehati-hatian dan manajemen risiko dalam melaksanakan kegiatan usaha, dengan menggunakan pendekatan risiko (Risk-based Bank Rating) baik secara individual maupun secara konsolidasi dengan cakupan penilaian meliputi faktor profil risiko (risk profile), Good Corporate Governance (GCG), Rentabilitas (earnings), dan permodalan (capital). Tujuan dari regulasi 
tersebut adalah untuk meningkatkan kepercayaan investor terhadap manajemen perusahaan yang tercermin dari harga saham di pasar modal.

Penelitian mengenai tingkat kesehatan bank yang dihubungkan dengan harga saham telah banyak dilakukan, antara lain , Arman, Sendi Gusnandar dan Shinta Dewi Herawati (2011), Iskandar Diah, (2012), membuktikan bahwa Capital Adequacy Ratio (CAR) berpengaruh signifikan terhadap harga saham. Sedangkan penelitian yang dilakukan oleh Vidyatama Ferik, dan Mardhono (2012), membuktikan bahwa Capital Adequacy Ratio (CAR) tidak berpengaruh signifikan terhadap harga saham.

Penelitian ini menggunakan risiko kuantitatif dari aspek profil risiko yaitu risiko likuiditas Good Corporate Governance diukur dengan melihat nilai komposit GCG yang terdapat dalam annual report, earnings dan aspek permodalan dengan menggunakan Capital Adequacy Ratio yaitu untuk mengukur kecukupan modal yang dimiliki oleh bank.

Para investor akan melihat seberapa besar kemampuan bank untuk mengelolah modalnya sendiri maupun modal yang berasal dari investor untuk menghasilkan laba yang tinggi. Hal ini akan memberikan sinyal positif pada investor untuk menanamkan dananya dan akan mempengaruhi harga saham bank tersebut.

\section{KAJIAN PUSTAKA DAN PENGEMBANGAN HIPOTESIS}

Penilaian tingkat kesehatan bank dengan menggunakan pendekatan berdasarkan risiko merupakan penilaian yang komprehensif dan terstruktur terhadap hasil integrasi profil risiko dan kinerja yang meliputi penerapan tata kelola yang baik, rentabilitas, dan permodalan. Kinerja bank yang digunakan pada penilaian tersebut, diukur dengan menggunakan rasio - rasio keuangan yang dapat dilihat dari laporan keuangan perusahaan yang menggambarkan kinerja keuangan dan kondisi keuangan perusahaan pada satu periode tertentu.

Penelitian ini menggunakan teori Sinyal, dimana teori Sinyal mengemukakan bagaimana seharusnya sebuah perusahaan memberikan sinyal kepada pengguna laporan keuangan. Sinyal yang diberikan dapat berupa good news yaitu berupa kinerja perusahaan perbankan yang mengalami peningkatan dari tahun ke tahun, sedangkan bad news dapat berupa penurunan kinerja yang semakin mengalami penurunan. Peningkatan komponen RBBR diharapkan dapat menjadi sinyal bagi para investor dalam menentukan keputusan investasi, sehingga nantinya akan berpengaruh terhadap fluktuasi harga saham perusahaan perbankan (Setyawan, 2012).

\section{Penilaian Tingkat Kesehatan Bank Umum terdiri dari:}

1. Penilaian Profil Risiko

Penilaian faktor profil risiko merupakan penilaian terhadap risiko inheren dan kualitas penerapan manajemen risiko dalam aktivitas operasional bank. Risiko yang wajib dinilai terdiri dari atas delapan jenis risiko yaitu risiko kredit, risiko pasar, risiko operasional, risiko likuiditas, risiko hukum, risiko stratejik, risiko 
kepatuhan, dan risiko reputasi. Dalam penelitian ini hanya menggunakan risiko likuiditas, yaitu risiko akibat ketidakmampuan bank untuk memenuhi kewajiban yang jatuh tempo dari sumber pendanaan arus kas, dan/ atau dari aset likuid berkualitas tinggi yang dapat diagunkan, tanpa mengganggu aktivitas dan kondisi keuangan bank

2. Penilaian faktor Good Corporate Governance GCG) Penilaian faktor GCG dalam penilaian tingkat kesehatan Bank Umum dengan menggunakan pendekatan risiko RBBR, bank wajib melaksanakan kegiatan usahanya dengan berpedoman pada prinsip GCG, yaitu transparansi (transparency), akuntabilitas (accountability), pertanggungjawaban (responsibility), independensi (independency) dan kewajaran (fairness).

Dalam rangka memastikan penerapan 5 (lima) prinsip dasar GCG, bank harus melakukan penilaian sendiri (self assessment) secara berkala.

3. Penilaian faktor rentabilitas

Penilain faktor meliputi evaluasi terhadap kinerja rentabilitas, sumber-sumber rentabilitas, kesinambungan (sustainability) rentabilitas, dan manajemen rentabilitas. Penilaian dilakukan dengan mempertimbangkan tingkat, trend, struktur, stabilitas rentabilitas bank, dan perbandingan kinerja bank dengan kinerja peer group, baik melalui analisis aspek kuantitatif maupun kualitatif

4. Penilaian Permodalan

Penilaian terhadap faktor permodalan meliputi evaluasi terhadap tingkat kecukupan permodalan dan pengelolaan permodalan. Dalam melakukan perhitungan permodalan, bank wajib mengacu pada ketentuan Bank Indonesia yang mengatur mengenai kewajiban penyediaan modal minimum bagi bank umum. Selain itu, dalam melakukan penilaian kecukupan permodalan ,bank juga harus mengaitkan kecukupan modal dengan profil risiko bank. Semakin tinggi risiko bank, semakin besar modal yang harus disediakan untuk mengantisipasi risiko tersebut.

5. Harga Saham

Harga saham merupakan harga suatu saham dari pasar yang sedang berlangsung. Harga saham dapat berubah setiap saat, oleh karena itu para investor menggunakan kesempatan ini untuk memperoleh keuntungan dari adanya perubahan harga saham tersebut. Keuntungan yang dimaksud adalah capital gain, yaitu selisih positif yang terjadi antara harga saat membeli dan harga saat menjual saham tersebut (Prabawa, 2010).

\section{Pengembangan Hipotesis}

Pengaturan likuiditas bank terutama dimaksudkan agar bank setiap saat dapat memenuhi kewajiban yang harus dipenuhi segera (Kuncoro dan Suhardjono, 2002). Risiko Likuiditas bank dapat diukur dengan menggunakan Loan to Deposit Ratio (LDR).

Signalling Theory menjelaskan alasan mengapa perusahaan memiliki insentif untuk melaporkan secara sukarela informasi laporan keuangan kepada pihak eksternal, yaitu untuk mengurangi asimetri informasi. Apabila bank mampu memenuhi kewajiban jangka pendeknya dan dapat meminimalisir risiko likuiditas, maka tingkat kesehatan bank dinilai baik yang diikuti dengan kepercayaan masyarakat 
terhadap kinerja bank. Kondisi bank yang likuiditasnya baik memberikan informasi sinyal positif kepada stakeholders bahwa kinerja bank tersebut baik. Sinyal yang baik tersebut mengindikasikan bahwa kinerja bank tersebut tidak bermasalah yang artinya bahwa penilaian atas bank tersebut dikatakan sehat sehingga akan meningkatkan minat investor dalam berinvestasi yang tercermin pada peningkatan harga saham. Penelitian yang dilakukan oleh Vidyatama dan Mardhono (2012), membuktikan bahwa Loan to Deposit Ratio (LDR) berpengaruh secara positif dan signifikan terhadap harga saham. Berdasarkan argumentasi di atas, secara umum dapat dirumuskan hipotesis sebagai berikut :

\section{H1 : Loan to Deposit Ratio (LDR) berpengaruh positif terhadap harga saham.}

Good Corporate Governance yang semakin baik menunjukkan kemampuan bank dalam mengelola manajemen untuk menjaga tingkat kesehatan bank. Kepercayaan tersebut akan dapat merubah permintaan dan atau penawaran harga saham perbankan yang selanjutnya akan berpengaruh terhadap kenaikan harga saham yang bersangkutan (Setyawan,2012).

Signalling theory menjelaskan alasan mengapa perusahaan memiliki insentif untuk melaporkan secara sukarela informasi laporan keuangan kepada pihak eksternal, yaitu untuk mengurangi asimetri informasi. Semakin baik kinerja GCG maka investor akan merespon positif melalui kenaikan harga saham. Berdasarkan argumentasi di atas, secara umum dapat dirumuskan hipotesis sebagai berikut :

\section{H2 : Good corporate governance berpengaruh positif terhadap harga saham.}

Rentabilitas bank adalah kemampuan suatu bank untuk mengetahui kinerja bank dalam menghasilkan laba selama periode tertentu, juga bertujuan untuk mengukur tingkat efektifitas, menganalisis atau mengukur tingkat efisiensi usaha dan profitabilitas yang dicapai oleh bank. Alat ukur rentabillitas atau earnings, pada penelitian ini lebih tepat menggunakan Return On Equity (ROE) karena variabel dependen pada penelitian ini yaitu harga saham termasuk ke dalam golongan equity. Para investor akan melihat seberapa besar kemampuan bank untuk mengelolah modalnya sendiri maupun modal yang berasal dari investor untuk menghasilkan laba yang tinggi

Tingginya rentabilitas menunjukkan bahwa kinerja bank tersebut baik dan dinilai sehat. Kondisi bank yang rentabilitasnya baik memberikan informasi sinyal positif kepada para stakeholders. Hal ini sesuai dengan teori sinyal yang mengatakan bahwa perusahaan yang berkualitas baik akan memberikan sinyal pada pasar dan para stakeholders. Sinyal yang baik tersebut mengindikasikan bahwa kinerja bank tidak bermasalah sehingga akan meningkatkan minat investor untuk berinvestasi yang dapat meningkatkan harga saham pada bank. Berdasarkan argumentasi diatas secara umum dapat dirumuskan hipotesis sebagai berikut:

\section{H3 : Return On Equity (ROE) berpengaruh positif terhadap harga saham.}

Permodalan adalah aspek kecukupan modal yang menunjukkan kemampuan dalam mempertahankan modal yang mencukupi dan kemampuan manajemen bank dalam mengidentifikasi, mengawasi dan 
mengontrol risiko-risiko yang timbul yang dapat berpengaruh terhadap besarnya modal bank. Aspek permodalan atau capital dapat diukur dengan menggunakan Capital Adequacy Ratio(CAR), merupakan rasio perbandingan modal sendiri bank dengan kebutuhan modal yang tersedia setelah dihitung margin risk (pertumbuhan risiko) dari akibat yang berisiko (ATMR). CAR yang semakin meningkat menunjukkan kemampuan bank yang semakin baik dalam mempertahankan kecukupan modalnya untuk menjaga kualitas bank agar tetap sehat. Kepercayaan investor dapat merubah permintaan dan atau penawaran harga saham perbankan yang selanjutnya akan berpengaruh terhadap kenaikan harga saham yang bersangkutan (Purwasih, 2010). Berdasarkan argumentasi di atas, secara umum dapat dirumuskan hipotesis sebagai berikut :

\section{H4 : Capital Adequacy Ratio(CAR) berpengaruh positif terhadap harga saham.}

\section{METODE PENELITIAN}

Populasi dalam penelitian ini adalah perusahaan sektor perbankan yang terdaftar di Bursa Efek Indonesia (BEI) dan menggunakan penilaian tingkat kesehatan Bank berdasarkan Risk-Based Bank Rating.

Pengambilan sampel dalam penelitian ini menggunakan teknik purposive sampling. Adapun penggunaan metode purposive sampling dalam penelitian ini adalah perusahaan perbankan yang memiliki kriteria sebagai berikut:

a. Perusahaan perbankan yang terdaftar pada Bursa Efek Indonesia (BEI) dan menggunakan penilaian tingkat kesehatan Bank berdasarkan Risk-Based Bank Rating dari tahun 2012-2013.

b. Perusahaan perbankan yang mempublikasikan annual report secara konsisten dan lengkap selama tahun pengamatan.

Data yang digunakan adalah data sekunder dan jenis penelitian adalah penelitian kuantitatif. Data diolah dengan program SPSS versi 19. Untuk pengujian hipotesis menggunakan taraf signifikansi sebesar 5\%

Teknik analisis data menggunakan model persamaan regresi linear berganda sebagai berikut:

$$
Y=a+\beta_{1} X_{1}+\beta_{2} X_{2}+\beta_{3} X_{3}+\beta_{4} X_{4}+e
$$

\section{HASIL DAN PEMBAHASAN}

Populasi yang digunakan dalam penelitian ini sebanyak 39 perusahaan dan sampel yang diperoleh dengan mendasarkan metode purposive sampling sebanyak 28 perusahaan yang memenuhi kriteria penentuan sampel.

Persamaan Regresinya sebagai berikut:

$$
Y=-8167,81+35,11 X_{1 b}+850,79 X_{2}+148,43 X_{3}+209,95 X_{4}
$$

\section{Pengujian Hipotesis}

\section{Hasil Uji t}

Berdasarkan tabel tersebut menunjukkan bahwa hipotesis 1, LDR berpengaruh positif terhadap harga saham memiliki nilai signifikansi sebesar 0,127 dan lebih besar 0,05, sehingga dapat disimpulkan bahwa hipotesis 1 ditolak. Sedangkan untuk hipotesis 2, hipotesis 3 dan hipotesis 4 menunjukkan nilai signifikansi kurang dari 0,05. Dengan demikian dapat disimpulkan bahwa hipotesis 2, hipotesis 3 dan hipotesis 4 diterima. Hal ini menunjukkan bahwa Good Corporate Governance (GCG), ROE dan 
CAR berpengaruh positif terhadap harga saham.

Jika bank telah melakukan aspek GCG dengan baik maka akan menimbulkan kepercayaan masyarakat kepada manajemen bank dan dampaknya harga saham menungkat. Demikian pula bank yang rentabilitasnya baik dan ditunjukkan dengan rasio ROE yang tinggi memberikan informasi sinyal yang baik kepada stakeholders. Sedangkan rasio CARmengindikasikan bahwa bankyang bersangkutan memiliki kecukupan modal yang baik dan sehat. Bank yang mampu memenuhi kecukupan modalnya mengindikasikan bahwa nilai perusahaan dari suatu bank akan baik dan prospek yang baik akan membuat minat investor tinggi, sehingga berpengaruh positif terhadap harga saham.

Ringkasan hasil pengujian hipotesis sebagai berikut:

$\begin{array}{cll}\text { Hipotesis } & \text { Keterangan } & \text { Hasil } \\ \text { H1 } & \begin{array}{l}\text { LDR berpengaruh positif terhadap } \\ \text { harga saham }\end{array} & \text { Ditolak } \\ & \begin{array}{l}\text { Good Corporate Governance (GCG) } \\ \text { berpengaruh positif terhadap }\end{array} & \text { Diterima } \\ \text { H2 } & \text { harga saham } & \\ & \text { ROE berpengaruh positif terhadap } & \text { Diterima } \\ \text { H3 } & \text { harga saham } & \\ & \text { CAR berpengaruh positif terhadap } & \text { Diterima } \\ \text { H4 } & \text { harga saham } & \end{array}$

\section{SIMPULAN}

1. Tingkat Kesehatan Bank dari aspek profil risiko dengan risiko likuiditas yang diukur dengan Loan to Deposit Ratio (LDR) tidak terbukti berpengaruh positif terhadap harga saham. Hal ini mengindikasikan bahwa baik buruknya risiko likuiditas tidak terlalu direspon oleh stakeholders.

2. Tingkat Kesehatan Bank dari aspek Good Corporate Governance (GCG) terbukti berpengaruh positif terhadap harga saham. Semakin baik GCG pada suatu bank maka akan mempengaruhi minat investor untuk menanamkan dananya pada bank tersebut dalam bentuk sahamdan meningkatkan harga saham.

3. Tingkat Kesehatan Bank dari aspek Rentabilitas atau Earnings terbukti berpengaruh positif terhadap harga saham. Semakin tinggi keuntungan yang diperoleh oleh bank akan memberikan sinyal yang baik kepada stakeholders dan memberikan respon positif kepada investor yang akan berdampak terhadap tinggi harga saham.

4. Tingkat Kesehatan Bank dari aspek permodalan terbukti berpengaruh positif terhadap harga saham. Kecukupan modal yang baik akan memberikan sinyal positif kepada stakeholders dan akan berdampak terhadap tingginya permintaan saham, sehinggaharga saham akan semakin tinggi. 


\section{Saran}

Penelitian ini hanya menggunakan satu profil risiko, yaitu risiko likuiditas dari delapan profil risiko. Oleh karena itu untuk penelitian selanjutnya diharapkan dapat menggunakan aspek risiko yag lain agar hasil penelitian lebih baik..

\section{DAFTAR PUSTAKA}

Arnan, Sendi Gusnandar dan Shinta Dewi Herawati. 2011. "Pengaruh Kinerja Keuangan Terhadap Harga Saham (Studi Pada Sub Sektor Perbankan Di Bursa Efek Indonesia)", Jurnal Bisnis dan Manajemen, Vol. 7 No. 2, Januari.

Bokhari, ljaz Hussain dan Syed Muhamad Ali. 2012. Determinant of Capital Adequacy Ratio in Banking Sector: An Empirical Analysis from Pakistan. Academy of Contemporary Research Journal.

Buyuksalvarci, Ahmet dan Hasan Abdioglu. 2011. Determinants of Capital Adequacy Ratio in Turkish Banks: A Panel Data Analysis. African Journal of Business Management Vol. 5.

Ghozali, Imam. 2011. Aplikasi Analisis Multivariate dengan Program IBM SPSS 19, BP UNDIP, Semarang. Iskandar, SE. M.Si, Diah, dkk. 2012. "Pengaruh Capital Adequacy Ratio (CAR), Loan to Deposit Ratio (LDR), Non Performing Loan (NPL), Dan Perbandingan Biaya Operasional Dengan Pendapatan Operasional (BOPO) Terhadap Harga Saham Pada Perusahaan Perbankan Di Bursa Efek Indonesia (Tahun 2008 - 2010)".

Kania, Imas Siti. 2012. "Pengaruh Perubahan Capital Adequacy Ratio (CAR), Return On Assets (ROA) dan Loan To Deposit Ratio (LDR) Terhadap Harga Saham Pada Perbankan Yang Terdaftar di Bursa Efek Indonesia (BEI) Periode 2008-2010", (Skripsi Fakultas Ekonomi Universitas Pasundan), Bandung. - Dipublikasikan

Kuncoro, Mudrajad dan Suhardjono. 2002. Manajemen Perbankan Teori Dan Aplikasi, Edisi Pertama Yogyakarta: BPFE-Yogyakarta.

Nurhartanto, Septiawan. 2010. "Effect Of Ratio OfCamels In Share Price (Empirical Studies Of Commercial Banks In Indonesia Stock Exchange Registered During The Period 2004-2009)", Artikel Undergraduate Program, Economy Faculty, Gunadarma University.

Purwasih, Ratna. 2010. Pengaruh Rasio Camel Terhadap Perubahan Harga Saham Perusahaan Perbankan Yang Go Public Di Bursa Efek Indonesia (BEI) Tahun 2006-2008". (Skripsi Fakultas Ekonomi Universitas Diponegoro), Semarang.

Peraturan Bank Indonesia No.13/1/PBI/2011 tentang : Penilaian Tingkat Kesehatan Bank Umum Setyawan, Aditya Wira Perdana .2012. “Pengaruh Komponen Risk Based Bank Rating Terhadap Harga Saham

Perusahaan Perbankan yang Go Public di Bursa Efek Indonesia (BEI) Tahun 2008-2011", (Skripsi Fakultas Ekonomi Universitas Diponegoro), Semarang - Dipublikasikan.

Vidyatama, Ferik dan Mardhono. 2012."Pengaruh Capital Adequacy Ratio (CAR), Return On Asset (ROA)

Dan Loan To Deposit Ratio (LDR) Terhadap Harga Saham Bank Pemerintah Di Indonesia Periode 
2004-2011", JESP Vol. 4, No. 2.

Yuanjuan, Li dan Xiao Shishun. 2012. Effectiveness of China's Commercial Banks' Capital Adequacy Ratio. Interdisciplinary Journal of Contemporary Research Business.

Zulbetti, Rita. 2012. Pengaruh Rasio-Rasio dan Faktor-Faktor Makroekonomi Terhadap Return Saham (Studi Empiris Pada Perusahaan Perbankan yang Terdaftar di Bursa Efek Indonesia Periode 2000-2010). Banking and Management Review Vol 1 No 1.

Jurnal Akuntansi Indonesia 
LAMPIRAN

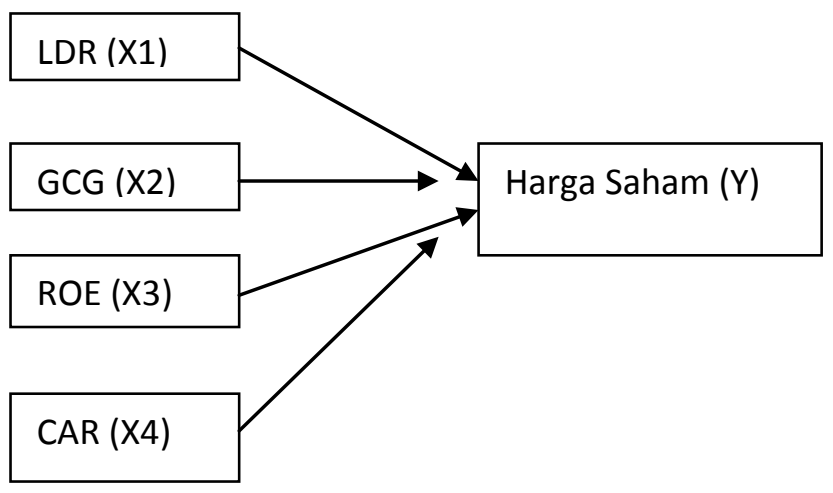

Gambar 1

Model Penelitian:

\begin{tabular}{|c|c|c|c|c|c|c|c|}
\hline \multicolumn{8}{|c|}{ Coefficients $^{\mathrm{a}}$} \\
\hline \multirow[b]{2}{*}{ Model } & \multicolumn{2}{|c|}{$\begin{array}{c}\text { Unstandardized } \\
\text { Coefficients }\end{array}$} & \multirow{2}{*}{$\begin{array}{c}\text { Stan } \\
\text { dardi } \\
\text { zed } \\
\text { Coeff } \\
\text { icient } \\
\mathrm{s} \\
\\
\text { Beta }\end{array}$} & \multirow[b]{2}{*}{$t$} & \multirow[b]{2}{*}{ Sig. } & \multicolumn{2}{|c|}{$\begin{array}{c}\text { Collinearity } \\
\text { Statistics }\end{array}$} \\
\hline & B & Std. Error & & & & $\begin{array}{l}\text { Toler } \\
\text { ance }\end{array}$ & VIF \\
\hline $\begin{array}{c}\text { (Const } \\
\text { ) }\end{array}$ & $-8167,812$ & 2375,693 & & $-3,438$ & ,001 & & \\
\hline LDR & 35,107 & 22,613 & , 141 & 1,553 &, 127 & ,946 & 1,057 \\
\hline GCG & 850,789 & 403,053 &, 210 & 2,111 &, 040 & ,792 & 1,263 \\
\hline ROE & 148,428 & 38,478 & ,412 & 3,858 &, 000 & ,688 & 1,454 \\
\hline CAR & 209,946 & 102,720 & ,225 & 2,044 & ,046 & ,648 & 1,543 \\
\hline
\end{tabular}




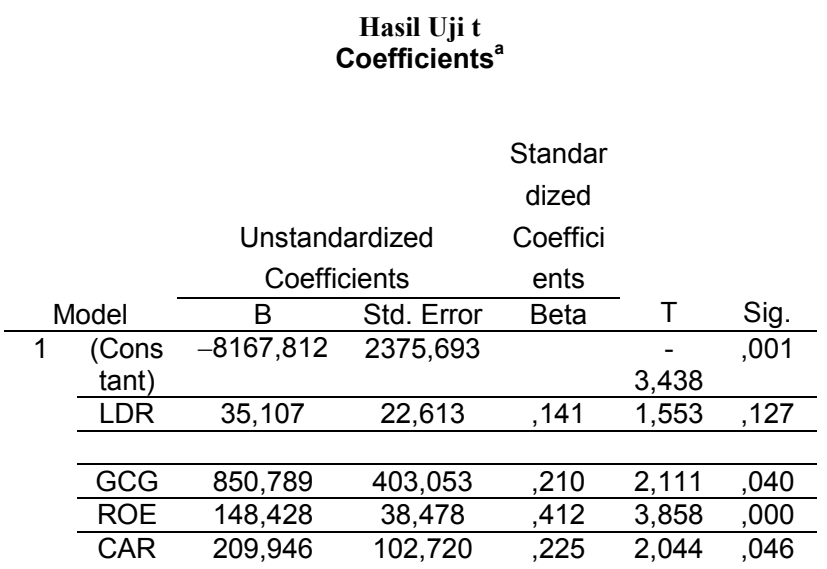

Jurnal Akuntansi Indonesia 